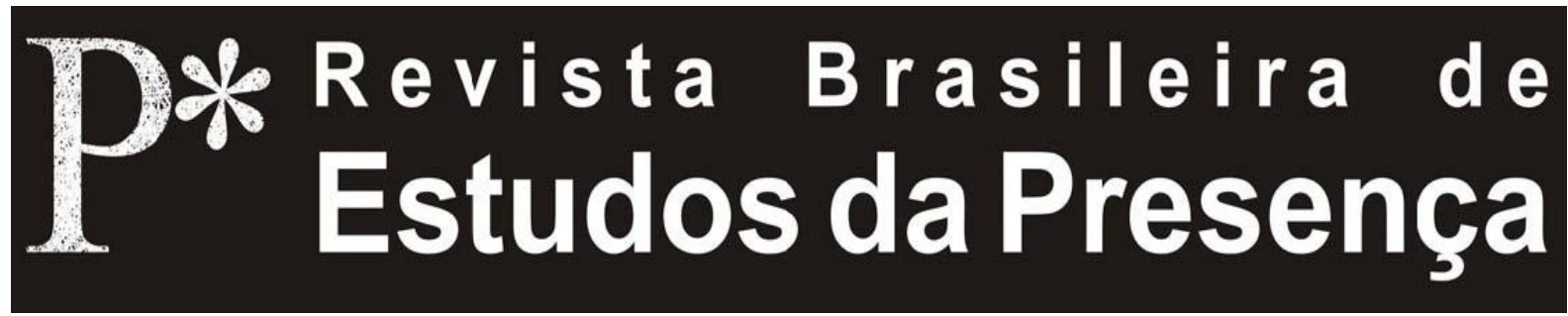

DOI - http://dx.doi.org/10.1590/2237-266034765

ISSN 2237-2660

\title{
O Paradoxo do Espectador do Teatro Laboratório
}

\author{
Bénédicte Boisson \\ Université Rennes 2 - Rennes, França
}

RESUMO - O Paradoxo do Espectador do Teatro Laboratório - Este artigo se debruça sobre a concepção de espectador no Teatro Laboratório de Jerzy Grotowski, concepção complexa e em constante evoluçáo. Se Grotowski procurou, ao longo dos diversos espetáculos do Teatro Laboratório, criar um verdadeiro encontro entre os atores e os espectadores - cuja relaçáo está no centro de seu teatro - ele rapidamente colocou em questão a eficiência da participação do espectador e da fusáo entre os espaços cênico e do público. $\mathrm{O}$ encontro que ele buscou suscitar em espetáculos como $O$ Príncipe Constante ou Akrópolis consistia em manter a distância do espectador em relaçáo àquilo que ele via e insistia na postura específica deste último.

Palavras-chave: Espectador. Relação Teatral. Jerzy Grotowski. Teatro Laboratório. Participaçáo.

ABSTRACT - The Laboratory Theatre Spectator's Paradox - This article focuses on the concept of spectator in the Laboratory Theatre of Jerzy Grotowski, a complex and ever evolving idea. If Grotowski sought, throughout various spectacles of the Laboratory Theatre, to create a true encounter between actors and spectators - whose relationship is at the centre of his theatre - he quickly put into question the efficiency of the spectator's participation and of the merging of scenic and audience spaces. The encounter he sought to foster in spectacles such as The Constant Prince or Akropolis consisted in keeping the spectators away from what they saw, insisting on the specific stance of the latter.

Keywords: Spectator. Theatrical Relation. Jerzy Grotowski. Laboratory Theatre. Participation.

RÉSUMÉ - Le Paradoxe du Spectateur au Théâtre Laboratoire - Cet article se penche sur la conception du spectateur au sein du Théâtre Laboratoire de Jerzy Grotowski. Conception complexe et en perpétuelle évolution. Si dans divers spectacles du Théâtre Laboratoire Grotowski a cherché à créer une véritable rencontre entre acteurs et spectateurs - dont la relation se trouve au centre de son théâtre - il a très vite remis en question l'efficacité de la participation du spectateur et la fusion entre la scène et la salle. La rencontre qu'il a cherchée à susciter dans des spectacles comme Le Prince Constant ou Akropolis consistait à tenir le spectateur à distance de ce qu'il voyait et insistait sur l'attitude particulière de ce dernier. Mots-clés: Spectateur. Relation Théâtrale. Jerzy Grotowski. Théâtre Laboratoire. Participation. 
Quando, em 1967, Jerzy Grotowski participa da entrevista que resultará no texto Teatro é encontro (Le théâtre est une rencontre) (Grotowski, 1971a), ele começa a ser descoberto na França e no mundo. Essa entrevista, cujo título parece evocar a relação entre palco e plateia, nunca menciona, de fato, explicitamente os espectadores, ou o faz apenas para denunciar a ideia de que no teatro tratar-se-ia de "fazer amor com o público" (Grotowski, 1971a, p. 56), e que isso implicaria na mercantilizaçáo dos atores. No resto desse texto, aparece essa instância geral de um outro, ao qual o teatro proporcionaria uma abertura. Jerzy Grotowski se concentra no encontro entre o diretor e o texto, entre o diretor e o ator, e entre essas três instâncias.

Para os dois, o diretor e o ator, o texto do autor é uma espécie de bisturi que nos permite abrir-nos a nós mesmos, transcendermos-nos, para encontrar aquilo que está escondido em nós e realizar o ato de encontrar os outros; dito de outra forma, de transcender nossa solidão. [...] O teatro é um ato engendrado por reaçóes e por impulsos humanos, por contatos entre as pessoas. É, ao mesmo tempo, um ato biológico e espiritual (Grotowski, 1971a, p. 55-56) ${ }^{1}$.

A relação entre ator e espectador está, no entanto, no cerne da própria definição do teatro pobre e é considerada como o único elemento verdadeiramente necessário para essa arte, que pode ocorrer sem o conjunto de seus meios técnicos e sem um palco, mas "[...] não pode existir sem a relação ator/espectador, sem a comunhão da percepção direta, viva” (Grotowski, 1971b, p. 17)2. Essa relação é objeto de numerosas experimentaçóes, particularmente a partir da instalaçáo de Grotowski no Teatro das 13 Fileiras em Opole. Em 1960, em Caim, espetáculo feito a partir do texto de Byron, depois em Shakuntala, a partir do texto de Kalidasa, espaços de atuação são propostos em meio aos espectadores, ou ainda a cena pode se tornar central. Mas é em 1961, com Os Antepassados, a partir do texto de Adam Mickiewicz, que aparece um único espaço que mistura atores e espectadores, completando a "[...] conquista do espaço no Teatro Laboratório, a partir da cena à italiana até a exploração total da própria sala, mesmo entre os espectadores" (Grotowski, 1971c, s. p.) ${ }^{3}$. Essas pesquisas continuam - com inflexóes notáveis, como veremos - nas criaçôes seguintes, algumas das quais tornarão o Teatro Laboratório conhecido internacionalmente: Kordian, baseado no texto de Slowacki (1962), Akropolis, a partir do texto de Wyspianski (de 1962, com cinco versôes sucessivas, até 1967), Dr. Fausto, de Marlowe (1963), 
O Principe constante, segundo o texto de Calderon-Slowacki (feito em 1965, com três versóes até 1968) e, enfim, Apocalypsis cum figuris (1968-1969). A cada espetáculo, um dispositivo cenográfico específico, a ser entendido, doravante, como uma articulação do espaço dos atores e do espaço dos espectadores, conduz a uma relaçáo particular dos espectadores com a obra. A abolição da rampa e a proposta de um espaço, às vezes único, são rapidamente consideradas como uma das inovaçôes mais marcantes do Teatro Laboratório. Assim, em 1962, quando Jerzy Grotowski é ainda quase um desconhecido na França, Raymonde Temkine apresenta seu trabalho, em Combat, da seguinte maneira:

O ator é uma espécie de feiticeiro que, para agir mais poderosamente sobre o espírito do espectador, se mistura a ele. A maior ousadia deste 'teatro-laboratório' é ir além, de maneira muito resoluta, do sacrossanto divórcio entre a cena e a sala. Em Opole, a sala é a cena; a cena é toda a sala. Não há mais espectadores passivos: eles são integrados ao espetáculo, os atores caminham próximos a eles, atuam ao lado deles e através deles. Em tais espetáculos, varia a repartição de pretos e brancos, se eu puder nomeá-los assim, conforme os esquemas de encenação que eu pude ver (Temkine, 1962 , s. p. $)^{4}$.

Essa conquista da sala pela cena se torna rapidamente um dogma para os estudiosos estrangeiros de Jerzy Grotowski, que ficarão decepcionados pelo tapume de madeira que materializa a separaçáo entre a cena e os espectadores em $O$ Principe constante. "Eles disseram, 'você é um traidor da ideia de osmose entre o espectador e o ator" (Grotowski, 1997, p. 51) , explica Grotowski a Richard Schechner em 1968. De fato, rapidamente, as experimentaçóes do Teatro Laboratório são vistas como a pesquisa de uma osmose, de uma comunhão entre atores e espectadores, até mesmo de uma assimilação entre esses dois polos que permite abandonar a ordem da representação para entrar na ordem do acontecimento ou do ritual, compartilhados e vividos juntos.

Entretanto, Jerzy Grotowski se mostrará rapidamente crítico em relação a tais ideias, questionando mesmo as suas pesquisas dos anos 1960-1963 ${ }^{6}$. Ainda que ele náo refute a tentativa de um encontro real, ele se volta particularmente para dois pontos: por um lado, a confusão entre aproximação física e psíquica; por outro lado, o esquecimento da especificidade da postura do espectador no teatro. Essa concepção complexa e em constante evoluçấo da relação 
ator-espectador no desenrolar do período teatral de Jerzy Grotowski será aqui explorada, utilizando tanto as declaraçóes e os escritos do diretor, quanto os testemunhos da recepção, na França, de $O$ Príncipe constante (1966, Théâtre des Nations, Paris) e de Akropolis (1968, Théâtre de l'Epée de Bois, Paris).

\section{A Necessidade de Outra Relação Teatral}

Os questionamentos que levam Jerzy Grotowski a se perguntar profundamente sobre a relação atores-espectadores entram, fortemente, em consonância com as preocupações do mundo teatral europeu dos anos 1950 e 1960, fazendo, ele também, a constataçáo de uma sociedade desunida e da necessidade do teatro afirmar sua especificidade face ao cinema e à televisáo. Isso implica, nessa época, a afirmação do teatro como arte da presença, reunindo, em um dado tempo e lugar, atores e espectadores, como arte ativa e de participação, em oposição ao cinema, mas implica, igualmente, o questionamento tanto da possibilidade de uma identificação comum com a peça ${ }^{7}$, quanto do distanciamento que tinha, entretanto, aparecido como uma solução alternativa ${ }^{8}$. As pesquisas de Jerzy Grotowski, assim como a recepção dos seus espetáculos na França, se inscrevem em tal contexto e parecem ser uma via para renovar uma relaçáo teatral que náo conseguia mais se sustentar por si só. Falando sobre o início de suas pesquisas, Jerzy Grotowski explica que:

No início, quando eu trabalhava com o tipo mais clássico de teatro, achava que o mais importante era evitar a rivalidade entre o teatro e o cinema. Entáo me perguntei: como podemos promover um encontro entre atores e espectadores que seja um encontro real, uma troca, algo que não pode ser feito em filmes ou na TV? (Grotowski, 1997, p. 45$)^{9}$.

Essas questôes levarão antes de tudo, a partir de um trabalho conjunto com o cenógrafo Gurawski, a uma exploração das relaçôes espaciais entre atores e espectadores, rapidamente associadas a uma participação dos espectadores, tratados como atores. Em Kordian, por exemplo, todo o espaço do teatro se tornava um hospital psiquiátrico, com os espectadores sentados sobre as camas e considerados pelos médicos-atores, da mesma maneira que alguns dos atores, como pacientes. O tempo da representaçáo e o da peça eram os mesmos e o teatro se tornava literalmente o espaço no qual a ação se desen- 
volve (Grotowski, 1997). Aconteciam numerosas experimentaçóes nas quais os atores cercavam os espectadores, lhes faziam perguntas, os tocavam, mas, muito rapidamente, constataram-se os limites de uma tal participação, nem suficientemente profunda, nem autêntica o bastante.

Mas percebemos que sempre havia trapaças do nosso lado. E, ao mesmo tempo, estávamos procurando um tipo de espontaneidade do público que é impossível em nossa sociedade. Procuramos reaçôes comuns que são apenas possíveis quando todos têm as mesmas crenças como referência, quando todos 'conhecem' bem a liturgia. Hoje há muitas meias-crenças - uma Torre de Babel - de modo que é impossível encontrar esse tipo de ritual (Grotowski, 1997, p. $47)^{10}$.

Assim, as tentativas para abolir a separação entre cena e sala por intermédio da integração dos espectadores à ação cênica não suscitam nem naturalidade, nem espontaneidade, nem entre os atores, nem entre os espectadores. O compartilhamento das açôes não implica, de fato, que a união superficial e a transformação dos espectadores em participantes venham a criar uma verdadeira comunidade. Para isso, seria necessário que as açôes realizadas tivessem um alcance simbólico partilhado, o que não é mais o caso em uma sociedade sem crenças nem referências comuns. Assim, a constatação de Grotowski une-se aqui a de Jean Vilar, evocando a comunhão tornada impossível no teatro na sociedade de seu tempo:

Temas cerimoniais e um ritual poético são concebíveis nos nossos dias? A resposta me parece fácil. Não, pois Deus não existe mais. Eu quero dizer: Nietzsche não foi o único a tê-lo matado, cada um de nós fez isso ou o faz, ou o mata ao menos por omissáo. [...] Então, talvez possamos, reencontrar um 'público crente' no dia em que o ateísmo for o mestre espiritual deste mundo. E quando eu digo 'público crente, eu quero dizer que acredita unanimemente em alguma coisa, talvez, na vida terrestre do homem. Mas, se olharmos em torno de nós, não há mais crença comum. Existe contradição. [...] Se, portanto, há divisão, como encontrar no teatro o espelho do tempo, a cerimônia e a comunhão? (Vilar, 1953, p. 113) ${ }^{11}$.

Finalmente, que o espectador esteja engajado na representação ou que ele permaneça sentado diante da cena, a aporia continua a mesma: o teatro não chega a superar uma desintegração que se situa no nível social. A modificação dos polos estruturais do teatro por 
intermédio da reuniáo dos espaços e da assimilação dos atores e dos espectadores - e, assim, a abolição das fronteiras dentro dessa arte não permite ao teatro apagar as divisóes existentes no mundo.

$\mathrm{Na}$ verdade, se Jerzy Grotowski visa uma forma de participação do espectador no espetáculo, isso náo pode ser entendido como o simples fato de tomar parte na ação cênica, mas, em uma acepção mais antropológica, como o estabelecimento de um modo de relaçáo diferente com o mundo, com o outro, e com os espetáculos, que náo depende da mobilização física do espectador. Lucien Levy-Bruhl ou Maurice Leenhardt (1947) definiram as características dessa participação, termo que qualifica o tipo de relação no mundo que eles observaram nas sociedades ditas primitivas. A participação supóe um universo concebido como um continuum, "[...] seres e objetos que podem ser, ao mesmo tempo, eles mesmos e algo diferente deles mesmos", a impossibilidade de conceber o indivíduo como distinto do grupo do qual ele pertence e participa, uma não separação entre o ser e seus "pertences" - objetos ou traços que lhe pertencem - a ausência de "[...] diferenciaçáo entre os domínios da ação e do pensamento, que tornaram-se, ao contrário, bastante distintos nas nossas sociedades complexas" (Queiroz, 1947, p. 13) ${ }^{12}$. Segundo as análises de Monique Borie, um deslocamento do teatro do campo da estética para o da "prática mítico-ritual", para encontrar "[...] a lógica plenamente operatória dos sistemas simbólicos nas culturas fundadas em um pensamento mágico e religioso" (Borie, 1989, p. 214), é pesquisado no Teatro Laboratório, tal como o fora anteriormente por Antonin Artaud. Um teatro em que o espaço, o tempo, os gestos e as palavras, "[...] tal como o signo religioso e o símbolo ritual, analisados pela Antropologia, têm valor de presença efetiva", em que os signos não são mais miméticos, mas "[...] eficazes no sentido pleno de 'eficácia simbólica' que a Antropologia analisa" (Borie, 1989, p. 214). A eficácia e a presença vêm assim desenhar "um novo modelo de ator [...], preocupado com uma energética" (Borie, 1989, p. 214) e, mesmo assim, póem igualmente o problema do espectador, que deve experimentar o tempo da representação. A questão não reside mais na redução de uma distância espacial ou na participação ativa dos espectadores, mas na possibilidade de um espetáculo em que os signos se tornem presenças. 


\section{Unidade, Percepçáo Direta e Distância}

Por outro lado, ignoramos o fato óbvio de que os espectadores estão, de qualquer maneira, desempenhando o papel de espectadores - eles são observadores! E quando os colocamos no papel de loucos, simplesmente perturbamos sua função natural de observadores ou - na melhor das hipóteses - de testemunhas; como consequência, suas reações não são naturais. A unidade de lugar, tempo e ação não foi realizada (Grotowski, 1997, p. 47-48) ${ }^{13}$.

Trata-se aqui da segunda lição tirada por Jerzy Grotowski das suas experimentaçôes com os espectadores: impor a estes últimos o mesmo papel dos atores durante a representação só pode subverter sua função teatral natural - que é observar, ser testemunha -, e também não cria a unidade de ação. Por isso, será principalmente observando a distância que o teatro implica, essa distância do olhar fundadora da teatralidade, que o Teatro Laboratório tentará unir cena e sala. Em Akropolis ou em O Principe constante, a separação entre atores e espectadores é claramente reivindicada, mesmo se ela não se traduz necessariamente em termos cenográficos. O papel proposto aos espectadores é bem diferente daquele dos atores: para eles, trata-se de manter seu papel de espectador, e sua postura é elaborada a partir de funçóes próprias ao público no dispositivo teatral. Assim, há "[...] dois conjuntos a dirigir: os atores e os espectadores" (Grotowski, 1971c, s. p.), que devem ser integrados e não dissolvidos um no outro, fazendo do espectador um ator.

Em Em Busca de um Teatro Pobre, Grotowski lembra que a arte nos diz respeito porque nos permite "ultrapassar nossos limites [...], preencher nosso vazio [...], realizar-nos" (1968, p. 20). Para conseguir fazê-lo, a identificação com o mito náo parece mais funcionar, o que resta é a confrontação com o mito (Grotowski, 1971b, p. 20). Ela mesma constituiria a unidade de ação procurada por Grotowski, comum aos atores e espectadores.

O que é a unidade de ação em um espetáculo? A unidade da ação não é a unidade da ação da peça. $O$ público sabe que não está vendo o verdadeiro Hamlet na Dinamarca. Deve-se sempre procurar pela verdade literal. O público pode assistir ao processo de confrontação - a história e seus motivos encontrando as histórias e os motivos das nossas vidas. Se há essa ação contraditória, esse encontro, se o público vê todos esses pequenos detalhes que fazem a confrontação alçar voo, se eles, como espectadores, tornam-se 
parte dessa confrontação, há unidade de ação (Grotowski, 1997, p. 52 ${ }^{14}$.

Para o ator, é preciso encarnar o mito, permanecendo próximo das suas experiências particulares, a fim de fazer ruir e cair a "[...] máscara da vida [...]. A exposiçáo do organismo vivo levado ao excesso, nos reporta a uma situação mítica concreta, a uma experiência da verdade humana comum" (Grotowski, 1971b, p. 22); ela pode funcionar como um tabu. $\mathrm{O}$ ator náo age mais, entáo, "[...] para os espectadores, ele deve atuar frente a frente com os espectadores, na presença dos espectadores; mais ainda, ele deve fazer um ato autêntico no lugar dos espectadores. Fazer um ato de autenticidade, de sinceridade extrema e organizada" (Grotowski apud Bablet, 1967, s. p. $)^{15}$. Diante desse ato total, é preciso um "público rico de inquietudes espirituais e de exigências intelectuais", um espectador "[...] que deseje se autoanalisar por meio de uma 'confrontaçáo direta com a representação"' (Lista, 1997, p. 178). Isso explica o desejo de manter pequenas medidas, mas permite, também, sublinhar o caráter interindividual da relação estabelecida. Aqui não se trata mais de cena nem de sala, ou de público, mas do que a confrontaçáo com o mito pode desencadear em cada um. Peter Brook, espectador de Akropolis, descreve muito bem esse fenômeno quando ele apresenta, em 1968, o filme originado do espetáculo. Para ele, a obra se situava além de toda comunicaçáo racional e a questáo do sentido desaparecia.

Por intermédio de uma linguagem de ritmos em constante evolução, perfeitamente controlados, eles criam um trabalho que se dirige diretamente a algo de profundamente guardado em cada um de nós. Assim, houve um momento no curso da representaçáo em que eu comecei a ter uma percepção muito diferente da minha respiração. Alguma coisa estava perturbada em mim, despertada, e se pôs a bater como em ritmo de jazz, mas o que bate como jazz é uma parte limitada do organismo. Ao passo que, nesse caso, alguma coisa se pôs a bater em ritmo com o espetáculo, de maneira muito mais completa, até que eu tivesse a sensação física de estar em contato com os atores. [...] De fato, eu tenho a sensação de que, graças a um domínio de elementos rítmicos profundos, a pulsaçáo da vida em um campo de concentraçáo pôde se revelar completamente em Akropolis e eu senti algo realmente ruim, realmente repugnante, algo que abafa todo o pensamento e toda a palavra (Brook, 2009, p. 27) ${ }^{16}$.

A mudança física evocada por Peter Brook, que parece ter experimentado as condiçôes de vida em um campo de concentração, não 
está ligada nem à identificação com os personagens, nem à participação ativa do espectador. Ele, à distância, sente-se em contato com os atores: graças, principalmente, ao ritmo; uma eficácia, no sentido antropológico, parece estar em jogo em Akropolis. Mas o teatro permanece uma arte coletiva e, se a percepção aí é direta, viva, se cada um é visto como um indivíduo, é o conjunto dos espectadores que deveria estar envolvido. Trata-se, de fato, de trabalhar a montagem na percep̧̧áo do espectador, montagem que necessita de um espectador presente, que se situe além da comunicação, mas que subentende igualmente a ausência de confusão entre cena e sala. Em 1993, Jerzy Grotowski, revendo seu percurso, define a diferença entre arte como apresentação e arte como veículo, que se situam nas duas extremidades da cadeia das artes performativas. No teatro de espetáculos, o trabalho se debruça sobre a visão que deve aparecer na mente do espectador. "Se todos os elementos são elaborados e perfeitamente montados (a montagem), na percepção do espectador aparece um efeito, uma visão, uma história; de certa maneira, o espetáculo não aparece sobre a cena, mas na percepção do espectador" (Grotowski, 1995, p. 181 $)^{17}$. O pensamento dessa montagem é de responsabilidade do diretor e seu resultado nasce da confrontaçáo de diversos elementos cênicos, sem relação com as motivaçóes interiores dos atores. "Se o espetáculo teatral funciona, vários espectadores vão captar mais ou menos a mesma montagem, em sua mente" (Grotowski apud Brook, 2009, p. 121$)^{18}$.

O espetáculo encenado e aquele percebido são, assim, claramente distintos, e é no espectador que a proposta cênica virá a se cristalizar. O efeito depende da precisão dessa proposta, mas também, necessariamente, da atenção dada ao espetáculo pelo público. O ser psicofísico do espectador é, entáo, mobilizado, com a ideia de uma cenografia que não seria apenas significante, mas igualmente eficaz para engendrar uma apreensão diferente da obra. Em O Príncipe constante, o exemplo é célebre, os espectadores separados da cena por um tapume se encontravam em uma situação de voyeurs, "[...] olhando abaixo um ato proibido, sua posição sugere uma arena ou uma sala de cirurgias" (Grotowski, 1971c, s. p.) ${ }^{19}$. Raymonde Temkine, lembrando-se desse espetáculo, diz do incômodo sentido e do fato de que, para ela, tratava-se menos de ser voyeur e mais de ser "testemunha fascinada mas impotente" $\left(1968\right.$, p. 117) ${ }^{20}$. Em Akropolis, é, 
sobretudo, a invasão do espaço pelos atores, a pressão posta sobre os espectadores que conta. Georges Lerminier fazendo, em 1968, em Le masque et la plume [A máscara e a pluma], a crítica deste espetáculo, testemunha sua experiência. Além da atuação excepcional dos atores, ele enfatiza a estranheza da relação com o público, ao mesmo tempo necessária e demasiada, o espectador se sente incomodado na proximidade com os atores, mas também, "anulado", "disperso" (Lerminier, 1968, s. p.), em uma nova forma de participação. Raymonde Temkine chega a uma constataçáo similar: esse espetáculo não é nem de comunháo, nem de participação. Os atores, ainda que próximos, parecem pertencer a outro mundo, do qual os vivos, os espectadores, estão excluídos. O próprio Grotowski, cujas declaraçôes estão em $L e$ Figaro, afirma que misturar ator e público permite, "[...] contrariamente ao que se poderia acreditar [...], criar um abismo entre eles, e não uma aproximação" (Grotowski, 1968, s. p.). Assim, nesses dois espetáculos, o que prevalece, é menos o sentimento de comunhão do que uma intransponível distância entre os atores e os espectadores. Estes últimos são chamados, em $O$ Principe constante, à sua função de olhar exterior à ação, ao passo que em Akropolis, ainda que os espectadores estejam distribuídos no espaço teatral e rodeados pelos atores, eles são os vivos diante dos mortos, e continuam a constituir o polo do real em meio à representaçáo.

A situação pessoal dos espectadores era totalmente diferente da situação dos personagens. Os espectadores funcionavam tanto como espectadores quanto dentro do contexto da peça. Eles são totalmente irrelevantes, incompreensíveis para os atores - do mesmo modo que os vivos são incapazes de entender os mortos (Grotowski, 1997, p. 50) ${ }^{21}$.

Assim, não é pela abolição de toda diferença entre atores e espectadores que o teatro ganha em eficácia e permite o encontro, mas, sobretudo, levando aos extremos, à incandescência, as funçôes atribuídas aos dois polos principais da representação que são os atores e os espectadores. Por um lado, o ator efetua uma doaçáo total dele mesmo, com total mestria; por outro lado, o espectador, pela própria posição que lhe é proposta, é lembrado coletivamente do seu papel de olhar, de ser alguém que percebe, radicalmente outro face ao ator. A partir deste outro lado do abismo, consciente de sua alteridade, ele pode se tornar a testemunha de uma representaçáo que consegue impor sua presença. 
Jerzy Grotowski, no decorrer da fase teatral, recusa rapidamente a ilusão de um encontro criado pela participação direta do público e pela abolição de toda fronteira entre os espaços da atuação - da ação - e do espectador - da percepção. Esse, nos espetáculos como Akropolis, Fausto, ou O Principe constante, não resulta da anulação da estrutura própria ao teatro, mas, principalmente, da procura de sua superação, mantendo, entretanto, as funções específicas de cada um dos polos do dispositivo teatral. Contudo, rapidamente essa pesquisa se revela insuficiente, e a procura de si, a abertura ao outro, far-se-áo doravante de maneira diferente, abandonando um contexto que impóe um encontro preparado, no qual cada um tem um papel preciso e sobre o qual o diretor tem plena consciência. Richard Schechner diz que Jerzy Grotowski, no final de Apocalypsis cum figuris, convidava alguns espectadores - sentados em bancos de madeira dispostos perto das paredes durante a representação - a juntar-se aos atores no fim do espetáculo, para estabelecer com eles uma interação direta (Schechner, 1997, p. 205).

Em 1947, retornando mais uma vez ao seu ideal de Teatro da Crueldade, Antonin Artaud escrevia:

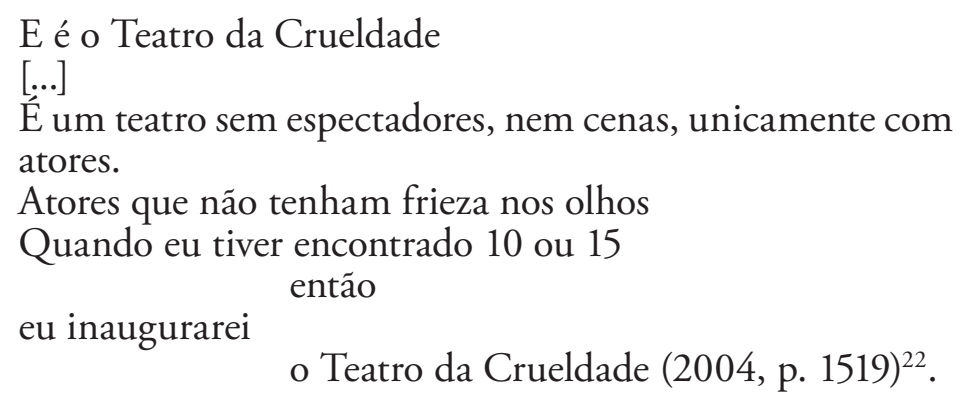

Por volta de 1970, o Teatro Laboratório começa, por sua vez, a explorar as vias do parateatro, no qual espectadores e público desapareciam, para dar lugar aos participantes. 


\section{Notas}

${ }^{1}$ No original: "Pour les deux, le metteur en scène et l'acteur, le texte de l'auteur est une espèce de bistouri qui nous permet de nous ouvrir nous-mêmes, de nous transcender, pour trouver ce qui est caché en nous et accomplir l'acte de rencontrer les autres ; autrement dit, de transcender notre solitude. [...]. [L]e théâtre est un acte engendré par des réactions et des impulsions humaines, par des contacts entre des personnes. C'est à la fois un acte biologique et spirituel" (Grotowski, 1971a, p. 55-56).

${ }^{2}$ No original: "[...] ne peut pas exister sans la relation acteur/spectateur, sans la communion de perception directe, 'vivante" (Grotowski, 1971b, p. 17).

${ }^{3}$ No original: "[...] la conquête de l'espace dans le Théâtre Laboratoire, à partir de la scène à l'italienne et jusqu'à l'exploitation totale de toute la salle même parmi les spectateurs" (Grotowski, 1971c, s. p.).

${ }^{4}$ No original: "L'acteur est une sorte de sorcier qui, pour agir plus puissamment sur l'esprit du spectateur, se mêle à lui. La plus grande hardiesse de ce "théâtre-laboratoire" c'est de passer outre très résolument au sacro-saint divorce de la scène et de la salle. A Opole, la salle, c'est la scène; la scène, c'est toute la salle. Plus de spectateurs passifs: ils sont intégrés à la représentation, les acteurs voisinent avec eux, jouent à côté d'eux et à travers eux. Selon les pièces, varie la répartition des noirs et des blancs, si je peux me permettre de les nommer ainsi d'après les schémas de mise en scène que j’ai pu voir" (Temkine, 1962, s. p.).

${ }^{5}$ No original em inglês: "They said, 'You'are a traitor to the idea of osmosis between the spectator and the actor" (Grotowski, 1997, p. 51).

${ }^{6}$ Em 1972, Jerzy Grotowski volta à França por ocasião das Journées Internationales du Théâtre des Nations (Jornadas Internacionais do Teatro das Naçôes) para proferir uma conferência relatando seus doze últimos anos de pesquisa e experimentação. Ele se mostra particularmente crítico em relação à pesquisa da "participação direta e ativa do público", descrita como um fracasso: "[...] minhas experiências sobre as relaçóes atores-espectadores efetuadas nos anos 1960-1963 não levaram à criação de um verdadeiro valor nem a uma situação verdadeiramente honesta: o público violado, obrigado por nós a participar, não foi natural e sentiu um certo incômodo. Nós conseguimos apenas nos intoxicar com uma certa cabotinagem” (No original: “Mes expériences sur les relations acteurs-spectateurs effectuées dans les années 1960-1963 n'ont pas abouti à la création d'une vraie valeur ni d'une situation vraiment honnête: le public violé, obligé par nous à participer, a manqué de naturel et ressenti une gêne certaine. Nous avons seulement réussi à nous intoxiquer avec un certain cabotinage" (Grotowski apud Varene, 1972, s. p.)).

${ }^{7}$ Isso é o que se compreende dos trabalhos dos anos de 1950 e 1951 do Centre d'Etudes Philosophiques et Techniques du Théâtre (Centro de Estudos Filosóficos e Técnicos do Teatro (Villiers, 1953)).

${ }^{8}$ Assim, Dort, que, em 1965, defendia o "sistema brechtiano" (Dort, 1986, p. 243) como o futuro de um teatro que não podia mais funcionar pela identificação, pois o espelho entre cena e sala estava quebrado, constatava (Dort, 1986, p. 239), alguns anos mais tarde, depois dos acontecimentos de 1968, que a era "cenocrática" que chegava talvez ao seu fim, 
isto é, "a posição própria da cena no centro do teatro: o caráter simbólico desse lugar" é questionado. Convém, entáo, "[...] elaborar novas formas [...], suscitar novas relações entre a cena, a sala e o mundo" (Dort, 1986, p. 281).

${ }^{9}$ No original em inglês: "At the beginning, when I worked in the most classical theatre, I thought that the most important thing was to avoid the rivalry between theatre and film. So I asked myself: How can we have a meeting between actors and spectators which is a real one, an exchange, something that cannot be done in film or on TV?" (Grotowski, 1997, p. 45).

${ }^{10}$ No original em inglês: "But we saw there was always cheating and trickery on our side. And at the same time, we were looking for a kind of spontaneity from the audience that is impossible in our society. We looked for common reactions which are possible only if people all have the same faith-references, if they "know" the liturgy well. Today there are many half-faiths - a Tower of Babel - so it is impossible to find this kind of ritual" (Grotowski, 1997, p. 47).

${ }^{11}$ No original: "Des sujets de cérémonies et un rituel poétique sont-ils concevables de nos jours? La réponse me semble facile. Non, car il n'y a plus de Dieu. Je veux dire: Nietzsche n'est pas seul à l'avoir tué; chacun de nous l'a fait ou le fait, ou le tue au moins pas omission. [...] Aussi bien, peut-être retrouverons-nous un public croyant le jour où l'athéisme sera le maître spirituel de ce monde. Et quand je dis 'public croyant', je veux dire croyant unanimement en quelque chose, et peut-être en la vie terrestre de l'homme. Mais si l'on regarde autour de soi, il n'y a pas de croyance commune. Il y a contradiction. [...] Si donc il y a division, comment retrouver au théâtre le miroir du temps, la cérémonie et la communion?” (Vilar, 1953, p. 113).

${ }^{12}$ No original: “[...] différenciation entre les domaines de l'action et de la pensée, devenus au contraire assez distincts dans nos sociétés complexes" (Queiroz, 1947, p. 13).

${ }^{13}$ No original em inglês: "On the other hand, we ignored the obvious fact that the spectators are anyway playing the role of spectators - they are observers! And when we put them in the role of madmen, we simply disturbed their natural fonction as observers - or in the best case - as witnesses; in consequence their reactions were not natural. The unity of place, time and action was not accomplished" (Grotowski, 1997, p. 47-48).

${ }^{14}$ No original em inglês: "What is the unity of action in a production? Unity of action is not unity of action of the play. The audience knows that they are not seeing the real Hamlet in Denmark. One must always look for the word-for-word truth. The audience can watch the process of confrontation - the story and its motives meeting the stories and motives in our lives. If there is this contraditory action, this meeting, if the audience sees all these small details which lift the confrontation into flight, if they, as spectators, become a part of this confrontation, we have unity of action" (Grotowski, 1997, p. 52).

${ }^{15}$ No original: "[...] pour les spectateurs, il doit jouer vis-à-vis des spectateurs, en présence des spectateurs; plus encore, il doit faire un acte authentique à la place des spectateurs. Faire un acte d'authenticité, de sincérité extrême et organisée” (Grotowski apud Bablet, 1967, s. p.).

${ }^{16}$ No original: "Par un langage de rythmes en constante évolution, parfaitement contrôlés, ils créent un travail qui s'adresse directement à quelque chose de très profondément enfoui 
en chacun d'entre nous. Ainsi, il y a eu un moment au cours de la représentation où j'ai commencé à avoir une perception très différente de ma respiration. Quelque chose était troublé en moi, éveillé, et s'est mis à battre en rythme comme en jazz, mais ce qui bat en jazz est une partie limitée de l'organisme. Alors que dans ce cas quelque chose s'est mis à battre en rythme avec la performance de façon beaucoup plus complète, jusqu'à ce que j'aie la sensation physique d'être en contact avec les acteurs. [...] En fait, j'ai le sentiment que, grâce à une maîtrise d'éléments rythmiques profonds, la pulsation de la vie dans un camp de concentration a pu se révéler au grand jour dans Akropolis et j'ai ressenti quelque chose de vraiment mauvais, réellement répugnant, quelque chose qui étouffe toute pensée et toute parole" (Brook, 2009, p. 27).

${ }^{17}$ No original: "Si tous les éléments sont élaborés et parfaitement montés (le montage), dans la perception du spectateur apparaît un effet, une vision, une histoire; d'une certaine manière, le spectacle apparaît non sur scène mais dans la perception du spectateur (Grotowski, 1995, p. 181). A arte como veículo, por sua vez, não procura criar montagens na percepção dos espectadores, "mas nos artistas que agem: nos atuadores" ["mais dans les artistes qui agissent: les actuants"] (Grotowski, 1995, p. 181).

${ }^{18}$ No original: "Si le spectacle théâtral marche, plusieurs spectateurs vont capter plus ou moins le même montage, dans leur mental” (Grotowski apud Brook, 2009, p. 121).

${ }^{19}$ No original: “[...] regardant en bas un acte interdit, leur position suggérant une arène ou une salle d'opérations". Legenda de um desenho que apresenta a cenografia de Le Prince Constant (Grotowski, 1971c, s. p.).

${ }^{20}$ No original: “[...] témoin fasciné mais impuissant” (Temkine, 1968, p. 117).

${ }^{21}$ No original em inglês: "The personal situation of the spectators was totally different from that of the characters. The spectators functioned both as spectators and within the contexte of the play. They are totally irrevelant, incomprehensible to the actors - as the living cannot understand the dead" (Grotowski, 1997, p. 50).

${ }^{22}$ No original: “Et c'est le Théâtre de la Cruauté. [...] C’est un théâtre sans spectateurs, ni scènes, avec uniquement des acteurs. Des acteurs qui n'aient pas froid aux yeux. Quand j'en aurai trouvé 10 ou 15 alors j’inaugurerai le Théâtre de la Cruauté” (Artaud, 2004, p. 1519).

\section{Referências}

ARTAUD, Antonin. [Le corps humain] [1947]. In: GROSSMANN, Evelyne (Org.). CEuvres. Paris: Gallimard, 2004, p.1519-1520.

BABLET, Denis. Les Techniques de l'Acteur. Rencontre avec Jerzy Grotowski. Les Lettres Françaises, Paris, 16 mar. 1967.

BORIE, Monique. Anthropologie Théâtrale et Approche Anthropologique du Théâtre. Bouffonneries: le théâtre qui danse, Holstebro, Lectoure, n. 22/23, p. 212-216, 1989.

BROOK, Peter. Avec Grotowski. Arles: Actes Sud-Papiers, 2009.

DORT, Bernard. La Vocation Politique [1965]; Une propédeutique de la réalité [1968]. In: 
Théâtres, Paris: Seuil, 1986. P. 233-248; P. 275-295.

GROTOWSKI, Jerzy. Interview with Grotowski [1968]. In: SCHECHNER, Richard; WOLFORD, Lisa (Org.). The Grotowski Sourcebook. London/New-York: Routledge, 1997. P. 36-53.

GROTOWSKI, Jerzy. De la Compagnie Théâtrale à l'Art comme Véhicule [1993]. In: RICHARDS, Thomas. Travailler avec Grotowski sur les Actions Physiques. Arles/ Paris: Actes Sud/Académie expérimentale des théâtres, 1995. P. 175-201.

GROTOWSKI, Jerzy. Grotowski veut créer l'Incompréhension. Le Figaro, Paris, 24 set. 1968, não assinado.

GROTOWSKI, Jerzy. Le Théâtre est une Rencontre [1967]. In: GROTOWSKI, Jerzy. Vers un Théâtre Pauvre. Lausanne: L'Âge d'homme, 1971a. P. 53-58.

GROTOWSKI, Jerzy. Vers un Théâtre Pauvre [1965]. In: GROTOWSKI, Jerzy. Vers un Théâtre Pauvre. Lausanne: L'Âge d'homme, 1971b. P. 13-24.

GROTOWSKI, Jerzy. Manuscrito de 1962. In: GROTOWSKI, Jerzy. Vers un Théâtre Pauvre. Lausanne: L'Âge d'homme, 1971c. S. p.

GROTOWSKI, Jerzy. Vers un Théâtre Pauvre. Lausanne: L'Âge d'homme, 1971d.

LEENHARDT, Maurice. Do Kamo. La Personne et le Mythe dans le Monde Mélanésien. Paris: Gallimard, NRF, 1947.

LERMINIER, Georges. Discurso. Le Masque et la Plume [programa radiofônico], 20 out. 1968. Arquivo online no site do INA. Disponível em: <http://www.ina.fr/video/ PHD99207079/theatre.fr.html>. Acesso em: 15/05/2010.

LISTA, Giovanni. Encyclopédie Mondiale des Arts du Spectacle dans la Deuxième Moitié du 20è siècle. Paris: Actes Sud, 1997.

QUEIROZ, Maria Isaura Pereira de. Préface [1971]. In: LEENHARDT, Maurice. Do Kamo. La personne et le mythe dans le monde mélanésien. Paris: Gallimard, NRF, 1947. P. 7-37.

SCHECHNER, Richard. Introduction to Part II. Paratheatre 1969-78; Theatre of Sources, 1976-82. In: SCHECHNER, Richard; WOLFORD, Lisa (Org.). The Grotowski Sourcebook. London/New-York: Routledge, 1997. P. 205-212.

TEMKINE, Raymonde. Bientôt une Biennale du Théâtre d'Avant-garde? Combat, Paris, 25 dez. 1962.

TEMKINE, Raymonde. Grotowski. Lausanne: La Cité, 1968.

VARENE, Françoise. Au Théâtre des Nations. Franche Autocritique de Grotowski. Le Figaro, Paris, 22 abr. 1972.

VILAR, Jean. Du Spectateur et du Public [1950]. In: VILLIERS, André (Org.). Théâtre et Collectivité. Paris: Flammarion, 1953. P. 109-115.

VILLIERS, André (Org.). Théâtre et collectivité. Paris: Flammarion, 1953. 
Bénédicte Boisson é professora assistente na área de Estudos Teatrais na Universidade de Rennes 2, na França. É pesquisadora associada ao CNRS, França. Tem publicado diversos trabalhos sobre copresença, relação teatral e estéticas cênicas contemporâneas, entre eles o livro, em colaboraçáo com Alice Folco e Ariane Martinez, La mise en scène théâtrale de 1800 à nos jours, pela Editora PUF, em 2010.

E-mail: benedicte.boisson@univ-rennes2.fr

Traduzido do original em francês por Weslin de Jesus Santos Castro (Universidade Federal de Sergipe) e revisado por Dominique Marie Philippe Geneviève Boxus (Universidade Federal Fluminense). Revisão técnica de Tatiana Motta Lima (Universidade Federal do Estado do Rio de Janeiro).

Recebido em 29 de outubro de 2012 Aprovado em 22 de dezembro de 2012 